to return to his battalion is remarkable without reckoning his recovery from an attack of trench fever, and from a gunshot fracture of the thigh.

Private C. (Australian infantry), aged 20, was wounded in the neck by a fragment of shell on April 28th, 1917, and was admitted to the 3rd Australian Casualty Clearing Station on the same day. He remembered nothing after being wounded with the exception that he had a slight recollection of being in a motor ambulance until $h \in$ became conscious after operation.

The wound of entry was on the left side, over the horizontal ramus of the lower jaw, which was splintered, but without solution of continuity. "The track then extended inferiorly and posteriorly to a large clot surrounding a wound of the left internal jugular vein, which was almost completely severed immediately below the level of the superior border of the thyroid cartilage. The left common carotid artery, immediately below the bifurcation, was slightly lacerated and contused, but the the bifurcation, was slightly lacerated and contused, but the level, and the thrombus extended into the proximal portions of the external and internal carotid arteries. The proximal and distal ends of the divided internal jugular vein were ligatured. I ligatured the left common, external and internal carotid arteries immediately beyond the limits of the injury and thrombus, and the intervening thrombosed portions of these vessels were removed. The left vagus nerve was found completely severed. The track was then followed to the fissured transverse process of a cervical vertebra (sixth), and from this position the shell fragment was removed.

The vagus nerve was sutured with catgut and the wound sutured, free drainage anterior and posterior to the sternomastoid being provided. The patient was in.the casualty clearing station for six days; he could only whisper; there was no hemiplegia; the pulse rate was 140 .

The remainder of the history I obtained for the most part from the patient. He was admitted to No. 5 General Hospital from the patient. He was admitted to No. 5 General Hospital on May 5th, 1917. The pulse was still 140, and this rate was maintained for about two weeks after the date of being wounded. healed on May 16 th, and he arrived in England on May 17th, healed on May 16th, and he arrived in England on May 17th,
1917. There was weakness of the left arm (inability to abduct) for six weeks after being wounded. By the end of June, 1917, he could. walk at a slow pace. He noticed that the left armpit and left side of the chest perspired very freely from about May 16th to June 16th, 1917. Improvement of voice was noticed by the end of June, 1917; the pulse rate was then about 100 . A note made on the medical history sheet previous to August 5th, admitted to "slight paresis deltoid and biceps." He was severe exertion made him feel giddy, and be was unable to do physical drill on account of coughing and sever vomiting do physical drill on account of coughing and

Between August 5th and November 10th, 1917, he was classifie

four times, and on each occasion the medical officer remarked four times, and on each occasion the medical officer remarked On his rapid pulse. He rejoined his battalion on November
10th, 1917, and was evacuated, suffering from trench fever, on February 2nd, 1918. The temperature remained high for one February 2nd, 1918. The temperature remained high for one
week; the pulse reached 120 , and remained rapid till the beginning of Aprir, 1918. He again rejoined his battalion in June, 1918. On September 2nd, 1918, he was evacuated for shell wound of the right thigh (compound fracture of femur), which became septic. T The highest temperature recorded in his notes was $103^{\circ}$, and the highest pulse rate 120 . He last vomited in November, 1918.

On January 16th, 1919; he was admitted to the 1st Australian General Hospital. The femur was firmly united in good positíon. On February 28th, 1919, he could wheel himself about in a wheel chair. There was slight hoarseness, but no dysphagia, and the appetite was good. The average pulse rate since arlmission while resting has varied between 80 and 90 . After wheeling himself at a rapid rate for 200 yords in a wheel chair the pulse rate rose to 144 ; after five minutes it fell to 108, and in fifteen minutes to $: 96$. Physical examination revealed and abnormality. $X$-ray examination after a bismuth meal showed abnormality. $X$-ray examination after a bismuth meal showed
that the stomach was normal in shape, position, and time of that the stomach was normal in shape, position, and time of
emptying. $X$-ray examination showed no abnormality of the emptying. X-ray examination showed no abnormality of the
transverse processes of the cervical vertebrae of the left side. 'The right vocal cord was natural, and moved freely; the left was perfectly white, but only moved very slightly. Speech was

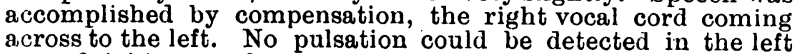
superficial temporal artery.

THE Belgian Royal Academy of Medicine, at a meeting on February 22nd, passed a resolution calling on the Government to enforce the laws against alcoholism and on the legislature to institute additional measures.

DR. ALICE HAMILTON has been appointed assistant professor of industrial medicine in Harvard Medical School. She is said to be the first woman to hold a teaching appointment in that university. She was for three years professor of pathology in the Women's Medical College of North-Western University and was bacteriologist to the Memorial Institute for: Infections in Chicago for eight years. Since 1910 she has been engaged in investigating industrial poisons for the Federal Department of Labour.

\section{Pettwomian Pertures}

on

\section{JAUNDICE: WITH SPECIAL REFERENCE TO TYPES OCCURRING DURING}

THE WAR**

By WILLIAM HENRY WILLCOX, C.B., C.M.G.,

M.D LOND., F.R.C.P.LOND., COLONEL A.M.S. PHYAICIAN TO OUT-PATIENTS, BT. MARY'S HOBPITAL, LONDON. LECTURE II.-PART I.

TOXIC JAUNDICE PRODUCED BY THE ACTION OF CHEMICAL POISONS.

BEFORE the war our knowledge of this form of jaundice was largely dependent on animal experiments. Cases occasionally occurred in man, and these were usually accidental or industrial in nature and often of medicolegal interest. Thus we were familiar with the jaundice occurring in poisoning by phosphorus, also that occasionally following the administration of arseno-benzol derivatives for therapeutic purposes, and of chloroform as an anaesthetic in those rare and tragic cases of delayed chloroform poisoning. Apart from these instances, the stabject of toxic jaundice was of academic rather than of practical interest.

Since the war experiments on the largest scale have unavoidably been carried out on munition workers and those engaged in work involving the use of dangerous poisons. We have become intimately acquainted with the many forms of toxic jaundice, and its dangers have been closely brought home to us, and in consequence the utmost precautions have been taken to prevent its occurrence in those exposed to risks of poisoning.

Tetrachloride of Ethane Poisoning.

This substance is a colourless liquid smelling like chloroform and having a specific gravity of 1.614 and a boiling point of $147^{\circ} \mathrm{F}$. It is of interest because the first cases of toxic jaundice observed ${ }^{1}$ in this country after the outbreak of war were due to the inhalation of the vapour of tetrachloride of ethane.

This substance, sometimes known as acetylene tetrachloride, was used in the preparation of cellulose varnish ("dope"), which was extensively employed in the manufacture of aeroplanes in order to give a firm airtight and waterproof coating to the calico stretched on the framework of the aeroplane wings. Several coats of dope had to be applied.

The dope was made by dissolving acetate of cellulose in a mixture of benzene, acetone, methylated spirit, and tetrachlorethane. It was a viscid colourless liquid smelling like chloroform, and on evaporation it gave off a mixed vapour of the volatile liquids which was 1.91 times as beary as air.

In September and October, 1914, the occurrence of several cases of illness associated with jaundice was noticed ${ }^{2}$ at the Hendon aeroplave factory. Cases of a similar nature were later observed at other aeroplane and seaplane factories. The outbreak of war naturally caused greatly increased activity in these factories, and the workers were employed overtime, so that any toxic in. fluences to which they might be exposed in their work would be greatly increased.

My first acquaintance with the subject was on November 5th, 1914, at my out-patient department at St. Mary's Hospital. The case was as follows :

\section{CASE I.}

G. M., a man aged 36, had been employed at the Hendon aeroplane factory since August 8th. On October 24th he felt ill; he had nausea and retching in the morning, some slight pain in the upper abdomen, and jaundice. He gave up work. The symptoms increased in severity, and at my examination there was marked jaundice, and the patient appeared seriously ill. Pulse 96, temperature $99.5^{\circ} \mathrm{F}$. The liver was felt about one inch below the right subcostal border in the right nipple line on inspiration. No abdominal tenderness was present; no line on inspiration. No abdominal tenderness was present ; no
anaemia. He said that the stools were pale and the urine highanaemia. He said that the stools were pale and the urine highcoloured. There was no history or evidence of syphilis or
alcoholism. The tongue was furred and dry. He thought his alcoholism. The tongue was furred and dry. He thought his illness was due to some condition associated with his work,
because ten other workers were affected similarly. On inquiry because ten other workets were affected similarly. On inquiry he thought this was composed of "collodion, chloroform, ether and acetone." He said that men who did not use thedope also

* Delivered before the Medical Society of London, April-May, 1919. 
suffered from the illness, but several of those who were using the dope had been taken ill. A diagnosis of toxic jaundice was made, and it was thought probable that some constituent of the dope was the cause of the patient's illness. I did not see the patient again, but I heard that: on November 14 th he was admitted to the Middlesex Hospital, and died there on the 26th. The case was referred to Mr. Luxmore Drew, H.M coroner, and he, after careful consideration, decided that a post-mortem examination should be held. This was made by Dr. Spilsbury who found a shrunken liver markedly bile-stained. Dr. T. M. Legge, Medical Inspector of Factories, Home Office, also investigated the case, and it was thought that the condition of the liver might be connected with the action of some poison to which the deceased was exposed during life.

A number of animal experiments were conducted by me relating to the possible toxic action of the constituents of the dope used at the aeroplane factory, and it was clearly demonstrated that one of the constituents-namely, tetrachlorethane(1) tion of the cells of and kidney

Careful investigations were made by Dr. Legge and myself into the health of other employees at the factory and into the conditions of work there.

All the facts were carefully placed before the learned coroner All the facts were carefully placed before the learned coroner,
Mr. Luxmore Drew; who made a most careful and painstaking Mr. Luxmore Drew; who made a most careful and painstaking
inquiry into the case, and as a result the jury found that death was due to degeneration of the liver caused by tetrachlorethane present in the cellulose varnish or dope used by deceased and to the vapours of which he was exposed during life.

A number of other cases were examined by me, of which the following are examples :

Case Ir.

C. L., male, aged 48, began work on August 10th, 1914, and left work on October 19th. He complained of constipation, sick headache, jaundice, nausea, and weakness, and some soresick headache, jaundice, nausea, and weakness, and some sore-
ness of the eyes. The urine was high-coloured, and the stools ness of the eyes. The urine was high:coloured, and the stools
were pale. The patient returned to work on November 9th, but were pale. The patient returned to work on November 9th, but
gave up work again on November 23 rd. On examination on gave up work again on November 23rd. On examination on was not tender. Slight but definite jaundice was present. The patient made a good recovery on being kept away from his work.

CASE III.

H. G., male, aged 53, commenced work on August 31st, 1914 and gave up work on October 27th. He was weak and ill, with loss of appetite. He had dryness of the throat. He was sick daily for fourteen days, and was light-headed at night. He had definite jaundice, the urine being high-coloured and the stools pale. There was no abdominal pain. The liver was slightly enlarged. Slight but definite icterus was present; no anaemia. Patient made a good recovery.

\section{CASE IV.}

J. R. P. H., male, aged 58, began to work at Hendon on June 3rd, 1914. He was working close to where the dope was used. He left work on September 2Ist. He was weak, felt drowsy, had no appetite, no energy, and the bowels were constipated: He had nausea, and on one occasion vomiting. Jaundice developed on September 14th; he became deeply jaundiced, with pale stools and high-coloured urine. He went to hospital on October $2 \mathrm{nd}$, and was in there seven weeks. He developed ascites while in hospital, and this increased. Oedema of the legs also developed. The urine on examination by Dr. J. M. Bernstein showed a deposit of leucin. On January Dr. 1915, paracentesis was performed by me, and 22 pints of clear iscitic fluid were drawn off. The fluid gradually reacoumulated and about three weeks ated, a $\mathrm{Dr} W$. 作 huid. The Dr. Ogle-Skan, under whose care he was, and he made a good recovery.

In none of the above cases was there a history of alcoholic excess or of syphilis. In several of the cases the Wassermann test for syphilis was applied, but in every case the result was negative.

On December 4th, 1914, Dr. T. M. Legge and I visited the Hendon aeroplane works. The smell of tetrachlorethane was very much in evidence, and at that time the ventilating arrangements by the plenum system were such that the heary vapour of the dope was blown about the large room of the factory instead of being extracted. A reference to a plan on which were marked the places where affected persons worked showed that several cases of jaundice occurred at quite considerable distances-for example, thirty or forty yards-from where the dope varnishing was done. The more severe cases occurred in persons who were actually using the dope or were near where it was used. On questioning some of those working in the factory at the time of our visit, it was found that several workers complained of nausea, biliousness, drowsiness, constipation, loss of appetite, nasty taste at the back of the throat, headache, and general malaise, these sym i)toms being no doubt due to the dope vapour.
Cases of illness : similar to those at Hendon have occurred in other factories where tetrachlorethane has been used. At the aeroplane faetory at Crayford two severe cases occurred, namely:

\section{Case v.}

E. H., female, aged 19, commenced work in August, 1914. About November 15 th she complained of the smell of the dope, of discomfort in throat, and drowsiness. On December 27th she became acutely ill with jaundice; there was vomiting and some abdominal pain. She beoame worse, and on January 2nd, 1915, vomited blood, was stuporose, and had convulsive twitchings. The stupor deepened into coma which lasted two days, when death supervened.

Necropsy.-The liver was hard and firm; it was very yellow, and showed marked congestion; it weighed $34 \frac{1}{2} \mathrm{oz}$. 'The kidneys show'ed marked yellow staining of the cortex, the pyramids being intensely congested. The medulla was yellow and congested. The kidneys weighed each $5 \mathrm{oz}$. The heart

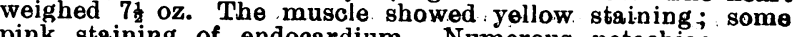
pink staining of endocardium. Numerous petechias were present over the surface of the left ventricle. The small intestine showed intense petechial heemonrhage over the surface. There was marked congestion of the small intestine. The spleen weighed 8 oz.; it was hard and frm. Microscopiosi exumination of the liver showed extensive necrosis, and in the kidney fatty degeneration: was present.

Case: vi.

M. W., female, aged 17, was wonking in the aeroplane factory for four montbs. On January 4th, 1915, she felt ill ; complained of discomfort in thnoat and general weakness. On January. 28th she gave up work. She complained of nausea, sickness, and constipation. Jaundice occurred at this date. She was examined on February 25th. There were intense jaundice stupor, and delirium. Neither the liver nor the spleen could be stupor, and delirium. Neither the liver nor the spleen could be
felt. There was some dullness in the flanks, which became felt. There was some dullness in the flanks, which became
resonant : when the patient rolled on to the side. The urine contained much bile and a trace of albumin; many epithelial and granular casts were preoent. Patieut became. Wores, passing into coms, and death occurred on February 28th.

Symptoms.

The following is a general summary of the symptoms of tetrachlorethane poisoning as it occurred from inhalation of the vapour in factories.

For some days the patients complained of general malaise, drowsiness while at work, loss of appetite, nausea, retching in the morning, unpleasant taste in the throat, constipation usually, and headache. Abdominal discom. fort:was present in some cases. After indefinite symptoms of this kind, lasting several days or even weeks, definite jaundice dereloped; and this was associated with pale stools and bilious urine. In severe cases, during the jaundice stage, icterus gravis might develop. The patient would vomit and become mentally confused, stuporose, or delirious. Puxpura, haemorrhages, or convulsions might occur and coma supervene and death result. In the terminal stage of the disease, which usually only lasted two or three days, suppression of urine occurred towards the end.

If the patient were removed from the influence of the poison in the early stages of the illness the symptoms cleared up, but it was some weeks before the jaundice became completely free, even if it were only slightly marked. In cases with deep jaundice the prognosis was bad and recovery was unlikely. In one very interesting case, described above, the patient recovered from the acute symptoms of a rather severe attack, but afterwards signs of contraction of the liver with portal obstruction developed, marked ascites resulting. It is interesting to record that after two operations of paracentesis the patient made a good recovery:

In the early stages of the illness the liver appeared to be slightly enlarged, no abdominal tenderness being present. Later the liver diminished in size. The urine contained in the late stages of a severe case much bile, a small amount of albumin, and numerous casts, epithelial and granular casts predominating. Leucin and tyrosin crystals were found in the unconcentrated urine in only one case.

Interesting clinical features of the action of tetra. chlorethane on the liver in the case of the aeroplane workers in this country.were: (1) The insidious onset of the symptoms. (2) The comparatively long duration of the acute stage when marked jaundice had supervened, thus distinguishing the cases from idiopathic acute yeltow atrophy of the liver. (3). The absence of marked pyrexia, thus distinguishing the cases from infective jaundjes. (4) The absence of anemia; thus distingaishing the cases 
from poisoning by poisons which cause marked blood destruction-for example, arseniuretted hydrogen, etc. (5) The marked depth of the jaundice, which was much deeper than is usually seen in cases of delayed chloroform poisoning and many other liver poisons.

There seemed to be a marked rariation in the susceptibility to the poison, and this corresponds to the varying susceptibility of patients to other liver poisons-for example, chloroform as decribed ${ }^{3}$ by Dr. L. G. Guthrie.

The jaundice appeared to be of the toxaemic or haemohepatogenous.kind, and the exact type of the symptoms was distinguishable from those of previously describod liver poisons. There was no doubt that the question of dosage played a very important part in the type of symptoins and in the incidence-rate of the illness. Thus the body was able to deal with very small amounts of the poison. When the quantity of poison absorbed became greater than the amount which could be dealt with then symptoms resulted, and these would: be progressive unless the patient was removed from the influence of the poison. The: effect of inareased dosege was well shown by the effects: of overtime and the increase in the quantity of dope varnish used in causing illiness; whereas under previous conditions no harm resulted to the bealth of the workers.

Treatment.

Prewention of poisoning by the vapour of tetrachlorethane was of much greater importance than the treatment of patients suffering from this intoxication. Effective measures were instituted in all factories where tetra. chlorethane was used. whereby the heavy vapour was remored by powerful extraction fans, which remoted the vapour at a low level and rapialy withdrew it from the workers. The Home Office took prompt aetion in the issuing of warning instructions, and in ensuring the provision of satisfactory measures for remoral af far as possible of any danger to workers from the vapour of the dope used.

The treatment of patients suffering from toxic jaundice due to "dope vapour" consisted, first, in their removal from all influence of the poison. Rest, light diet contain. ing ample carbohydrate, including dextrose or honey, and a much reduced amount of fat and pratein, saline aperients and general hygienic measures were all that were necessary in mild cases.

In cases with marked jaundice alkalis should be given by the mouth in full doses-for example, sodiun citrate and sodium carbonate, $\frac{1}{2}$-drachm doses of each in solution every two or three hours; also, by rectum, 3 drachms of sodium bicarbonate and 4 drachms of glucose dissolved in $10 \mathrm{oz}$. of water every eight hours. Where symptoms of icterus gravis threaten, intravenous or subcutaneous injections of normal saline containing 2 drachms of sodium bicarbonate to the pint should be given twice daily until the toxic symptoms. improve.

This line of treatment should be adopted in cases: of toxic jaundice due to other chemical poisons-for example, trinitrotoluene, delayed chloroform poisoning, etc.

\section{Experimental Observations.}

Experiments were instituted to test each of the constituents of the dope and the dope itself as regards the toxic action of their vapour on the liver.

For each experiment a large glass chamber (desiccator) was used. In the bottom of this were placed daily $10 \mathrm{c.cm}$. of the liquid to be tested. A perforated zinc plat form was stretched across the middle of the chamberthat is, half-way up. On this were placed the animals to be experimented: upon. The top of the chamber was covered with a perforated zinc roof. Rats were selected as the most suitable animals. The animals were lept in the glass chamber for eight hours a day for a week.

The liquids tested were dope, tetrachlorethane, acetone, benzene, and methylated spirit respectively. Two rats were placed in each chamber, five experiments being oaxried out together.

The rats thus exposed to dope vapour and tetrachlorethane vapour became very drowsy and slept all day. After removad from the chamber they remained drowsy for some little time, and on some occasions they were quite ataxic in gait, falling over on to their sides. After an houn or more usually they fed and became active. These animals did not gain in weight during the week's treatment.
In the experiments with acetone, benzene, and methy lated spirit the animals. were drowsy while exposed to the respective vapours, but on removal from it they imme diately became lively and fed well. No ataxic symptoms were observed. All these animals gained markedly in weight during the week.

After seven days' treatment the animals were killed, and post-mortem examinations were made on them by Dr. Spilsbury and myself. The tetrachlorethane rats showed marked changes in the liver to the naked eye, there being fatty degeneration and bilestaining present. "The "dope" rats showed similar changes but less marked. The rats exposed to the vapour of benzene, acetone, and methylated spirit showed no changes in the liver to the naked eye:

Careful microscopical examination of the organs showed marked fatty deposition and cloudy swelling in the liver and kidneys of rats exposed to dope vapour and tetra chlorethane vapour, but no abnormal change in the animals exposed to the other vispours. Rats. were also exposed to the action of dope vapour and tetrachlorethane vepour for five weeks. Marked diminution: in size: in the liver occurred in each case. The lifer and kidneys were pale on section. They showed cloudy swelling and fatty degeneration.

The above experiments showed conolusively that tetra chlorethane was a powerful liver poison, and also they showed that dope vapour was a liver poison, and that the poisonous property of dope vapour was: due to tetra. chlorethane being present in it.

In 1909. I mado'several experiments: with tetrachlorethane on. cats and rats in order to determine the anaesthetic effect of the drug. The vapoun was found: to be a poxperful anaesthetic, but after removal from the vapour it was a long time before the animal recovered from the effects, sometimes twenty-four hours or more being required. It was obvious that tetrachlorethane was much more poisonous than chloroform. Abont this time experiments were carried out by Dr. Veley, F.R.S., ${ }^{5}$ in the Physiological Laboratory of the University of London; and these showed that, weight for weight, tetrachlorethane was 2.8. times as powerful a tissue poison as chloroform.

Dr. B. H. Spilsbury has made very careful pathological investigations in several fatal cases of poisoning by tetrachloride of ethane. He found in the cases of relatively short duration marked degenerative changes in the liver, kidney and heart, and that fat was deposited in the cells of the liver and kidney and often in those of the heart muscle. Where the patient had lived for some time before the fatal termination, fat was present to a much. less extent or might bo absent. In these cases. there was marked destruction of areas of the liver cells and their place was taken. by newly-formed fibrous tissue-" replacement cirrhosis."

Owing to the great danger to which workers were exposed, the use of tetrachlorethane as a constituent of "dope" was given up, a good substitute having been discovered. Tetrachlorethane poisoning has been described at some length because it is a typical example of a poisan causing toxic jaundice.

In consequence of the importance of "toxic jaundice" from an industrial point of view, it was added in 1915 to the list of diseases to be notified to the Chief Inspector of Factories at the Home Office, London.

Trinitrotoluene.

Cases of toxic jaundice due to trinitrotoluene absorption were first observed in 1915, and numerous deaths from toxic jaundice caused by it were reported in 1916 and since. The general symptoms and pathological changes produced by trinitrotoluene resemble closely in many respects those caused by tetrachlorethane. A point of difference is that the former is associated with blood destruction and some cases show a severe anmemia, while in the latter this characteristic is little if at all marked.

Trinitrotoluene is a yellow powder which is often crystalline; sometimes it is in the form of fused yellowish brown lumps. It is used by munition workers for filling shells. The main channel of absorption of the poison appears to be through the skin, and the danger is increased by the presence of grease or oil. The skin and hair become stained yellow. In a few cases dermatitis has occurred on the hands, wrists; face; and neck, sssociated with itching and desquamation. More raroly a raised 
erythema may occur on the trunk, and affecting also the arms, thighs, and legs. Usually dermatitis is absent.

The poison may be inhaled in the form of dust or vapour, and a certain amount of dust may be swallowed. Dr. Benjannin Moore, ${ }^{6}$ after a good deal of experimental work on the subject, considers that the skin is the main entrance, and this is undoubtedly correct. The symptoms commence after a varying interval of a few days to several months of exposure-listlessness, pallor of the face, with sometimes eyanosis, and a pinched appearance occur. Nausea, distaste for food, and a bitter taste are early symptoms. Inhalation of the dust causes a burning in the throat and nose with excessive secretion, accompanied by cough and tiglitness of the chest. Constipation, depression, giddiness, and often faintness are early symptoms, and morning vomiting often occurs. After a duration of these preliminary symptoms for a varying period, sometimes quite sliort, jaundice commences, and often becomes deep, with pale stools and bilious urine. At this stage the liver is somewhat enlurged, and can be felt on palpation. 'These symptoms indicate grave changes in the liver associated with catarrh of the tiner bile ducts, and resulting biliary obstruction.

Should the function of the liver cells become seriously impaired, symptoms of icterus gravis may appear, owing to autointoxication. The patient becomes irritable, restless, and delirious, vomiting occurs, and a condition of stupor follows. Convulsions, or subsultus tendinum, may occur, and Cheyne Stokes breathing is commonly present. Coma ensues, with often an extensor plantar reflex, and sometimes exaggerated lnee-jerks and ankle clonus.

Haemorrhage in the form of haematemesis, melaena, or epistaxis is common at this stage, and death commonly results within three days of the onset of these symptoms.

The blood changes in trinitrotoluene jaundice have been carefully studied 7 by Captain M. J. Stewart, R.A.M.C. Out of fourteen cases examined, in three there was severe anaemia of the "pernicious" type, the colour index being greater than 1. A neutrophile leucopenia was present in nine of the cases; in only one case did a neutropliile leucocytosis occur. A lymphocytosis occurred in nine of the cases. He was of opinion that a progressive failure of the leucoblastic function of the bone marrow occurred.

The macroscopic and microscopic changes in the organs have been carefully studied ${ }^{6}$ by Spilsbury, I'urnbull, Stewart, and others.' In the liver cell degeneration, often associated with fat deposition, occurs early. This is accompanied by microscopic signs of catarrl of the bile ducts in the portal areas and round cell infiltration there. As the cell degeneration advances necrosis occurs and the liver tissue becomes replaced by fibrous tissue.

'To the naked eye, in the early stages the liver would be enlarged and on section have a uniform yellowish appearance due to the uniform degenerative changes often of a fatty nature tater the liver is shrunken and areas of dark reddish colour appear intermingled with the 'yellowish bile stained areas. The former represent the newly formed replacement fibrous tissue, and this is often most marked in the auterior marginal region. 'The kidney and heart muscle usually show marked degenerative clianges of a fatty type.

Treatment.

The treatment of trinitrotoluene jaundice should be on the lines laid down for the similar coudition in tetra. chlorethane poisoning, which has been fully described by me. ${ }^{4}$ Remarkable recoveries of three grave cases energetically treated on these lines have been publislied by Dr. Barbara Crawford. ${ }^{8}$ In these cases definite signs of icterus gravis had developed, but, following the administration of zij of sodium bicarbonate daily and $6 \mathrm{oz}$. of a saturated solution of the same salt by the rectum, recovery occurred.

Dr. R. Murray Leslie ${ }^{9}$ has described a very interesting case of severe type which recovered after the administration of sodium bicarbonate 30 grains every two hours. Dr. W. Bower ${ }^{10}$ has also described a case slowing symptoms of atrophy of the liver, which recovered after treatment on the above lines.

In December, 1976,11 an official paimplrlet on trinitrotoluene poisoning was published by the Ministry of Munitions. In this a clinical test of the urine for the poison or its products, discovered by Mr. J. Webster, F.I.C, was desoribed. Since then "a modification of
Webster's test has been published ${ }^{12}$ by F. Tutin, whereby fallacies due to the taking of drugs such as rhubarb, senna, cascara, etc., containing antinraquinone derivatives, can be excluded.

Webster's test has enabled a more accurate knowledge of the mechanism of T.N.T. industrial poisoning to be gained. Thus it was found that when the skin of workers was impregnated with the poison, the urine gave Webster's reaction for many days after exposure. On the other hand, poison taken into the alimentary tract could not be detected after twenty-four hours from its administration. This prolonged skin absorption will explain some of the cases where the onset of symptoms of poisoning takes place after removal from the work.

\section{Dinitrobenzene.}

This substance, which has been used for many years in the manufacture of explosives, is a yellowish crystalline powder, the channels of absorption of which are similar to those for trinitrotoluene.

The poison has a very marked action on the red blood corpuscles, causing severe anaemia, dyspnoea and cyanosis the latter being due to the formation of methaemoglobin.

The effects on the blood are by far the most prominent and earliest feature, but after prolonged exposure to the poison degenerative changes may occur in the liver, and an obstructive catarrh of the fine bile ducts derelop. In such cases toxic jaundice will occur, and fatal symptoms of icterus gravis are liable to supervene.

Picric Acid.

Picric acid (trinitrophenol) has been used largely as an explosive. It often causes an irritative dermatitis in workers exposed to the dust. Absorption of the poison into the system causes symptoms similar to those of dinitrobenzene, and in very severe cases toxic jaundice and icterus graris may result.

\section{Dinitrophenot.}

This substance, which is sometimes used in munition factories, causes symptoms similar to picric acid, except that dermatitis is less marked. Two fatal cases of toxic jaundice from it have been published. ${ }^{13}$

\section{Chloroform.}

After the administration of this as an anaesthetic toxic jaundice occasionally develops. 'The symptoms, linown as delayed chloroform poisoning, often conimence two days or so after the irnmediate effects of the anaesthetic have passed away. Vomiting, jaundice which is often only of slight degree, and nervous symptoms developing into those of "icterus gravis," is the common course of such cases, which commonly terminate fatally within a very few days.

Case vir.

The following is a typical case. In February, 1916, a boy aged 12 was operated on for appendicitis at St. Mary's Hospital. He stood the operation well, and recovered from the immediate effects of the anaesthetic. Three days after the operation he became drowsy, and vomiting occurred on several occasions definite but not deep jaundice was now observed. The drowsiness rapidly passed into stupor, followed by coma, and death ness rapidly passed into stupor, followed by coma, and death symptoms of icterus gravis being about forty-eight hours. Dr. Spilsbury carried out pathological investigations in this case, and found intense degeneration of the liver cells, with excessive deposition of fat in them.

A cousiderable number of these cases have been carefully investigated during recent years. An invariable post. mortem condition is intense degeneration of the liver cells with great deposition of fat in them; degenerative fatty changes are also found in the kidney and lieart. At some period of the illness signs of acid intoxication (acetone and diacetic acid in the urine) usually occur,

'The incidence of delayed chloroform poisoning is greater in children, and a predisposition to the condition is un. doubtedly a pre-existing acid intoxication. In a discussion on this subject ${ }^{14}$ at the Royal Society of Medicine, in February, 1912, it was pointed out that the excessive restriction of food before an anaesthetic was likely to act as a predisposing cause to an acid intoxication which would greatly increase the risk of delayed chloroform poisoning. The free administration of sugar and carbohydrate foods before an anaesthetic was recommended as a prophylactic. 
I am strongly of opinion that careful examination of the urine for acetone and diacetic acid should always be made before an anaesthetic is administered, and if these are present it is well for the operation to be postponed if possible, and certainly chloroform should not be used.

The late Dr. Leonard Guthrie, whose early demise we all greatly deplore, was very interested in the not infrequent occurrence of these cases in children. On February 1st, 1907, he read an able paper on delayed poisoning by anaesthetics, and expressed the opinion that a predisposing cause was a pre:existing fatty condition of the liver. ${ }^{3}$ Recent research has tended to confirm the correctness of his view.

ARSENIURETTED HYDROGEN.

This is an intensely powerful gaseous poison. Accidental cases have occurred from inhalation of the impure hydrogen evolved when acids act on metals, such as iron, which contain arsenic, for example, in balloon filling, etc. The gas causes very intense destruction of the red blood corpuscles, and also is a powerful poison to the liver cells.

The symptoms occur within a few hours of exposure, and are characterized by extreme anaemia, vomiting, weakness, rigors' haematemesis, haematuria, and melaena. Janndice occurs as a result of the excessive production of bile pigments; and the obstruction caused by the viscid bile and the catarrh of the fine bile ducts. This symptom is not a prominent one, and in some cases does not develop. The terminal symptoms are those of toxaemia due to auto. intoxication-namely, those of icterus gravis.

Phosphoretted Hydrogen.

This is an extremely poisonous gas, having an action very similar to that of arseniuretted bydrogen.

In 1908 several deaths occurred on ships from symptoms similar to the above as a result of exposure to the gases evolved from ferro silicon, which was part of the cargo. This is a solid substance made in France, and used for hardening steel. It commonly contains as impurities calcium phosphide and calcium arsenide.

Dr. Wilson Hake in $1910^{15}$ investigated the gases evolved from ferro-silicon by the action of moisture, and found them to consist of a mixture of phosphoretted hydrogen and arseniuretted lydrogen in the : proportion of 8 to 1 . Dr. Copeman, for the Local Government Board, conducted a careful investigation into the dangers associated with the transport of ferro-silicon, and as a result effective preventive measures were instituted by the Board of Trade.

\section{Arsenobenzol Derivatives.}

These have been very extensively used since the discovery by Ehrlich of salvarsan in 1910 and neo-salvarsan in 1912. Since the war compounds of the same composition as the above-namely, "kharsivan" and "neo kharsivan"-liave been manufactured in England, and other arsenobenzol derivatives are extensively used therapeutically. These substances have a powerful toxic action on the liver cells, and an intense degeneration with much fat deposition is found in the liver and kidney in fatal cases.

After the administration of salvarsan there are generally produced some slight symptoms due to the direct toxic action of the drug-namely, slight vomiting, looseness of the bowels, and a temperature rising a degree or so. These symptoms only last for about twenty-four hours, and usually no others occur. Very occasionally, however, after a quiescent period of one or two days, within four days from the administration usually, symptoms of profound toxaemia occur, and the prognosis in such cases is extremely grave. These symptoms are undoubtedly due to an autointoxication, and are such as occur in acute yellow atrophy of the liver. 'Thus an abnormal mental condition-for example, irritability and delirium, often associated with slight jaundice-develops, the patient becomes stuporose, convulsions may occur, and the breath ing may be Cheyne-Stokes in character. Coma supervenes, and death results usually after two or three days from the onset of these grave symptoms. It was thought that these grave nervous symptoms were the result of the action of the arsenic compound on the central nervous system, but this theory was disproved by investigations inade by Mr. J. Webster, F.I.C., and myself, ${ }^{16}$ in which it was shown that arsenic was absent from the central nervous system in these fatal cases. There is no doubt that these toxaenilc symptoms are due to autointoxication following the loss of hepatic function consequent on the destructive effect of the arsenobenzol compound on the liver cells.

The symptoms above described must be carefully dis. tinguished from those of acute arsenical poisoning, such as vomiting, diarrhoea, rashes, etc. When these occur after arsenobenzol compounds, they are probably due to im purities or decomposition of the preparation.

In consequence of the danger of occurrence of grave toxaemia from arsenobenzol compounds the dose has been wisely reduced from the original 0.6 gram of salvarsan 0.9 gram neo-salvarsan recommended by Ehrlich. Thus it is much safer to give repeated doses of 0.3 gram kharsivan or 0.45 neo-kharsivan at intervals. It was shown in our paper, already referred to, that after an intravenous injec tion of 0.5 gram of salvarsan, arsenic could be detected in the urine and faeces for three weeks. Hence, in order to avoid possible dangers of liver degeneration and resulting autointoxication, it is wise that, even with the smallev doses of $0.3 \mathrm{gram}$, an interval of two or three weeks should elapse between each dose.

A very interesting case was recorded ${ }^{17}$ by Lieut. Colonel R. A. Veale and Captain B. H. Wedd, R.A.M.C., in which death resulted from symptoms of icterus gravis afte two days' illness. In this case there was an interval of five weeks from the last of a course of eight injections of 0.6 gram of novarsenobenzol.

\section{TOLUYLENE-DIAMINE.}

The action of this drug in the production of toxic jaundice in dogs has been described when discussing the pathology of jaundice. Toluylene-diamine in dogs lias a specific effect on the intrahepatic bile capillaries, causing an obstructive inflammatory catarrh with consequent deep jaundice.

Phosphorus Poisoning.

The symptoms of acute phosphorus poisoning have been known for many years, and in the light of our recent knowledge of toxic jaundice the description of these cases is most interesting, and affords an excellent example of toxic jaundice.

'Thus the primary stage is one of gastro intestinal symptoms due to the irritant action of the poison. After a varying interval of $a$ few days this is followed by jaundice and the typical symptoms of "icterus gravis," or acute yellow atrophy of the liver, which are generally fatal within two or three days. Pathological examinations liave proved that phosphorus has a most powerful action on the liver, causing an intense degeneration, associated with fatty engorgement of the cells, with resulting loss of function and autointoxication.

\section{Musiriroom Poisoning.}

Poisonous fungi eaten in mistake for edible mushrooms produce intense degeneration of the liver cells with symptoms of autointoxication often associated with jaundice. A recent fatal case of mushroom poisoning has been in. vestigated by Dr. Spilsbury, to whom I am indebted for this account.

A man, aged 24, while visiting Epping Forest collected a number of fungi, some black, some dark, and some yellow which he took home and ate for his supper, thinking they were edible mushrooms. A few hours after the meal vomiting and diarrhoea set in, and these symptoms passed into stupor and coma, death occurring about sixty hours after the meal.

Post morten intense degeneration with great deposition of fat was found in the liver cells, and advanced degenerative changes was found in the liver cells, and advanced degenerative change. with deposition of fat were present in the cells of the kidney and heart muscle. No signs of gastro-intestinal irritation were found. The cause of death was undoubtedly an autointoxication resulting from impaired hepatic function.

A companion who also partook of the mushrooms suffered shortly afterwards from vomiting and diarrhoea lasting for twenty-four hours, but no grave symptoms followed.

SNake Bite.

The venom of snakes of the viper order has a specific action on the blood, causing alteration of its coagulability and commonly extensive extravasation in the part affected. Local and sometimes general jaundice may occur after the bites of such snakes. The primary effect in the causation of jaundice is due to the great blood destruction produced.

Conclusions.

A review of the above examples of toxic jaundice shows that there is a common pathological explanation of all. 
Degeneration of the liver cells, blood destruction, and production of a catarrh of the intrahepatic bile ducts are in varying respective degree the causation of the effects produced. Jaundice is a symptom which may occur early or late, or may, indeed, be absent, according to which causal factor predominates.

Dosage in relation to quantity and mode of administration of the poison, idiosyncrasy, age, state of health, and the type of poison determine the exact nature of the symptoms produced. Thus, after chloroform administration, arsenobenzol compounds, or gaseous poison such as arseniuretted hydrogen, where a relatively massive dose is rapidly administered and absorbed, the autointoxication consequent on sudden loss of liver function may result in rapidly fatal symptoms in which jaundice is not prominent. With other poisons where the absorption is slow, such as tetrachlorethane and trinitrotoluene, the changes in the liver are gradual and often considerable replace. ment fibrosis may take place in areas previously occupied by cells which have undergone degeneration and necrosis. Obstructive changes, due to catarrh of the finer bile ducts, occur, and jaundice is consequently a marked feature. Should the patient recover from the threatened symptoms of autointoxication, he may be faced with symptoms of portal obstruction (ascites, etc.) owing to the cirrhotic changes in the damaged liver.

When toxic jaundice occurs it is an indication that some poison has produced a certain pathological change in the liver resulting in an obstructive catarrh. This structural change and its resulting effect-namely, jaundice-remain long after all the causal poison has been excreted from the body. Hence toxicological tests for the causal poison in cases of toxic jaundice may be entirely negative. One finds the serpent's trail by the effects it has produced, but the poison itself has passed from the body.

\section{REFERENCES}

1 A Fatal Case of Poisoning by Tetrachloride of Ethane, Lancet, Decomber 26th, 1914

. The Taundice due to Tetrachlorethane Poisoning, a New Type amongst Aeroplane Workers, Lanoet, March 13th, 1915. Willcox, Spilsbury, and Legge: An OutTransactions of the Medical Society of London, vol. xxxviii, 1915.

3 Dr. L. G. Guthrie: Transactions of the Society of Anaesthetists, February lst, 1907, vol. viii, p. 117.

4W. H. Willex: The Treatment of Toxic Janndice due to Tetrachlore inane Poisoning, BRitise MEDICAL JouRnaL, February 26th, 1916. 5 Dr. Veley, F.R.S.: Proc. Roy. Soc., Series B, vol. 82, 1910

6 Srecial Discussion on Toxic Jaundice in Munition Workers, Proc. Roy. Soc. Med., January 23rd, 1917.

7 Captain M. J. Stewart, R.A.M.C.(T.) : Toxie Jaundice in Munition ol:kers, Lancet, January 27th, 1917.

Barbara G. R. Crawford: Toxic Jaundice with Atrophy of the Liver, BRITIBH MEDICAL JuURNAL, February 26th, 1916.

Proc. Roy. Soc. Med., February, 1917.

10 W. Bower: Atrophy of Liver, T
MiDICAL JoorNAL, May 4th, 1918. MEDiCal JodRnaL, December 16th, 1916

12 Frank Tutin : A Modification of Webster's Test for the Presence of T.N.T. in Urine, Lancet, October $26 \mathrm{th}, 1918$.

3 Barral et Martin: Intoxication par le dinitro phenol, Lyon : International Association of Medical Museums, Bulletin No. VII, May, 1918.

vol. v, Part I. Poisonous Gases liak : On Ferro-silicon, with Special Reference to the 16 W. H. Willcox and J. Webster: The Toxicology of Salvard BRITIsH MEDICAL JodRNAL, April lst, 1916

Lieut.-Colonel R. A. Veale, R.A.M.C.(T.), and B. H. Wedd,

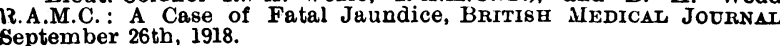

\section{fftemeraitdr :}

\section{MEDICAL, SURGICAL, OBSTETRICAL.}

SWIMMING IN THE TREATMENT OF PARALYSIS.

iT is sometimes forgotten and at other times never realized that in the treatment of all forms of paralysis the most important factor in success is the co-operation of the patient. He must be taught that no return of voluntary movement is possible unless he exercises his will, and he must be encouraged by every possible means to attempt every day the voluntary movements he has lost. When paralysis is due to disease or injury of the lower motor neurones massage and electrical treatment are necessary bo maintain the nutrition of the inactive muscles. In the tase of disease or injury of the upper motor neurones, on the other hand, massige and electricity have not the same value, and the voluntary efforts of the patient are of paramount importance. Keeping this principle in view, it is evident that the patient who is paralysed in his lower extremities, even if he retains some power in his leg muscles, is handicapped in locomotion by having to carry the weight of his body. If he is placed in a bath this burden is in great part removed, and he can exercise his limbs freely without running the risk of giving them too much to do. This is not the only advantage. The exercise obtained by swimming, or attempts at swimming, exerts a favourable influence on the body metabolism, and, what is quite as important, the realization that he is not so inactive or so disabled as he appeared to be when making his feeble and irksome attempts to walk is a mental stimulus to the patient of the utmost value Finally, the pleasure obtained from the bath is an induce. ment to the patient to persevere, and compares very favourably with the tedious routine involved in performing daily exercises against resistance while lying on the flat of his back in bed.

A few months ago a small swimming bath was constructed at the Tooting Special Surgical Military Hospital under the direction of Lieut.-Colonel D. K. McDowell, C.M.G., and has been in continuous use for treating patients suffering from paraplegia, hemiplegia, and other disabilities. The bath is $18 \mathrm{ft}$. long by $9 \mathrm{ft}$. broad, and the depth of water approximately $3 \frac{1}{2} \mathrm{ft}$. The water is kept at a temperature of $92^{\circ}$ to $94^{\circ} \mathrm{F}$., and is changed every day. In the case of spinal injuries with paraplegia, the degree of paralysis is no bar to the employment of this treatment, as it is possible for a man, although completely paralysed in his lower extremities, to learn to swim with his arms alone. In the process of learning assistance can be given by an orderly, or still better by the use of "water-wings," which give the patient all necessary support.

It is well known that many paraplegic patients are premated from making use of the voluntary power they possess by the presence of spasticity, and it is generally agreed that re-education of voluntary power is the best method of overcoming the involuntary spasm. It is not surprising, therefore, to find that practice in swimming in water kept at a comfortable temperature has been of great value in reducing spasticity in several cases.

Speaking generally, the results obtained at the Tooting Military Hospital by this method have been so favourable as to encourage the idea that a swimming bath must become in the future an essential part of the equipment of any hospital which undertakes the treatment of paralysed patients.

As almost every muscle and every joint is exercised in the art of swimming, the treatment can be applied to a number of different conditions in addition to those already mentioned. It would not be too much to expect favourable results from its use in the treatment of stiff joints, and of the many forms of disability which follow wounds and sepsis of the trunk and extremities.

Any therapeutic method which can be carried out by the patient himself, and which removes from his mind the idea that only the efforts of others are necessary for his cure, is deserving of a warm welcome in these days.

$$
\text { E. Farquhar Buzzard, M.D., }
$$

Colonel, A.M.S .
Consulting Physician to the London District

\section{A LARGE HERNIA IN A MALE CHILD.}

A sMall black boy aged about 7 years was brought to the hospital for treatment for a swelling in the scrotum which was said to have existed "for a long time." On the right side of the scrotum was a swelling about 12 inches in circumference extending half-way down the thigh. The swelling was resonant on percussion, and was obviously a hernia; it was irreducible.

It appeared doubtful whether the abdominal cavity would be large enough to contain the contents of such a large hernia, but I resolved to operate. The sac was found to contain, so far as I could ascertain, the whole of the large intestine, from the ileo-caecal valve to the sigmoid flexure, including the appendix and great omentum. With difficulty this mass was reduced into the abdominal cavity, and the opening at the neck of the sac obliterated.

The patient made an uninterrupted recovery, and was discharged with a sound scar which showed no sign of bulging.

Port Sudan.

Nö̈L E. Waterfield, M.B., B.S.Lond. F.R.C.S.Eng. 